\title{
Autologous Ilium Grafts: Long-Term Results on Immediate or Staged Functional Rehabilitation of Mandibular Segmental Defects Using Dental Implants after Tumor Resection
}

\author{
Duohong Zou, PhD, MD; ${ }^{* \dagger}$ Wei Huang, MD; Feng Wang, MD;* Shen Wang, MD;* Zhiyong Zhang, MD;* \\ Chenpin Zhang, PhD, MD;* Darnell Kaigler, DDS, PhD; ${ }^{\ddagger}$ Yiqun $\mathrm{Wu}, \mathrm{PhD}, \mathrm{MD}^{\star}$
}

\begin{abstract}
Background: It is a challenge for clinicians to restore oral function in patients with segmental defects of the mandible because of tumor extirpation. Dental implant therapy following vascularized autologous ilium grafts is an effective method to restore oral function in patients with mandibular segmental defects.
\end{abstract}

Purpose: The aim of this retrospective study was to investigate the long-term clinical outcomes of ilium grafts combined with immediate or staged mandibular dental implant therapy to restore craniofacial defects resulting from tumor resection.

Materials and Methods: Over a 5-year period (2000-2004), 32 patients who underwent mandibular segmental resection for tumors were treated with vascularized ilium grafts to augment bone volume. Seventeen patients received phase I therapy (immediate placement of implants), and 15 patients underwent phase II therapy (delayed placement of implants). A total of 110 dental implants were placed in these patients for mandibular restoration of the defective areas. Information regarding implant success and survival rates, marginal bone loss, soft tissue inflammation, complications of prosthesis, and patient satisfaction for the 8 to 12 years following oral reconstruction was obtained from patient records.

Results: Although there was mild evidence of bone graft resorption, the vascularized autogenous ilium bone grafts were successful in all patients. The cumulative patient survival and success rate of the implants were $96.4 \%$ and $91.8 \%$, respectively. The mean peri-implant bone resorption ranged from 1.0 to $1.2 \mathrm{~mm}$ over the 8- to 12-year follow-up period. The annual mean number of complications/repairs was from 0.11 to 0.07 per patient during the 8- to 12 -year follow-up. Over $80 \%$ of the patients were fully satisfied with their restoration of oral function.

Conclusions: This study demonstrates that reconstruction of mandibular segmental defects because of resection of mandibular tumors using dental implants therapy combined with vascularized autogenous ilium grafts is an effective method to restore oral function.

KEY WORDS: dental implant, ilium, mandibular segmental defects, oral function reconstruction, tumor, vascularized autogenous bone grafts

\section{INTRODUCTION}

Following tumor resection involving segmental mandibulectomies compared with marginal or rim

${ }^{\star}$ Professor, Departments of Oral and Craniofacial Implant and Oral and Maxillofacial Surgery, School of Medicine, Ninth People's Hospital Affiliated with Shanghai Jiao Tong University, Shanghai, China; ${ }^{\dagger}$ associate professor, Department of Dental Implant Centre, Stomatologic Hospital \& College, Anhui Medical University, Key Lab. of Oral Diseases Research of Anhui Province, Hefei, China; ${ }^{\ddagger}$ associate professor, Department of Periodontics and Oral Medicine in School of Dentistry, University of Michigan and Michigan Center of Oral Health Research (MCOHR), Ann Arbor, MI, USA mandibulectomies, severe continuity defects often remain, which result in very challenging functional rehabilitation and can significantly diminish quality of life. ${ }^{1-5}$ Therefore, the goal of therapy in these patients is to restore oral functional activity and esthetic

Reprint requests: Prof. Yiqun Wu, Ninth People's Hospital Affiliated with Shanghai Jiao Tong University, School of Medicine, Shanghai 200011, China; email: yiqunwu@hotmail.com

(C) 2013 Wiley Periodicals, Inc.

DOI 10.1111/cid.12169 
appearance in order to enhance quality of life. However, the complete reconstruction of the segmental mandibular defect remains a major clinical challenge. ${ }^{6}$ Studies have demonstrated that placement of dental endosseous implants is a widely accepted and scientifically substantiated therapeutic option for reconstructing oral function of the edentulous jaw. ${ }^{7,8}$ Since the 1980s, the employment of dental implants has been an integral part of the rehabilitation protocol for reconstruction of oral function in cancer patients following segmental mandibulectomy. ${ }^{9}$ However, sufficient bone volume still remains the limiting factor for placement and long-term stability of dental implants.

The repair of bony defects of the jaws using free vascularized tissue grafts, particularly of the mandible, has become a reliable procedure in recent years because it offers the potential for good functional and esthetic outcomes. ${ }^{10-12}$ Compared with nonvascularized autogenous bone grafts, the advantages of vascularized grafts include their insertion at the time of the initial surgery, the simultaneous supply of soft tissue, additional vascular supply in compromised irradiated tissue, and the primary placement of the implants. With the advent of vascularized osseous free flaps over the past 30 years, reliable mandibular reconstruction can be achieved, with success rates of over $90 \% .{ }^{13-17}$ To achieve complete continuity in the mandible, four donor sites (fibula, iliac crest, radial forearm, and scapula) become the primary sources of vascularized bone and soft tissue for tissue reconstruction. Compared with other donor sites, the iliac crest can offer a unique advantage over others in terms of bone quality and quantity. ${ }^{18,19}$ No other free tissue transfer can achieve the same degree of vertical height augmentation and quality of bone achieved by the ilium bone flap. This makes it an ideal graft for mandibular reconstruction, particularly when osseointegrated implants are considered. ${ }^{20}$ However, the morbidity associated with the iliac crest harvest limits its popularity.

Complications may develop after functional reconstruction of mandibular defects using dental implants combined with autologous ilium grafts, namely periimplant bone resorption, peri-implantitis, and implant failure. Relative to the donor site, ilium grafts are also associated with other disadvantages, such as gait disturbance, paresthesia of the lateral thigh, hernia, and extended healing times. ${ }^{21}$ Furthermore, recurrences of oral cancer are common and may lead to loss of the entire reconstruction. Therefore, it is important to evaluate long-term clinical outcomes of dental implant therapy combined with autologous ilium grafts in the reconstruction of mandibular segmental defects.

Many studies have reported efficacious results for reconstructing oral function with implants based on autologous ilium grafts in cases with mandibular defects. ${ }^{22-26}$ However, few reports have evaluated longterm functional outcomes (over a 10-year period). Based on the above considerations, the current study evaluated the results of mandibular reconstruction using dental implant therapy combined with vascularized ilium bone grafts over a period of 8 to 12 years. The aim of this study was to investigate the long-term clinical outcomes of immediate or staged dental implant therapy in mandibular rehabilitation secondary to tumor resection.

\section{MATERIALS AND METHODS}

\section{Patients Selected}

From January 2000 to October 2004, 43 patients received free ilium grafts from the Department of Oral and Maxillofacial Surgery and the Department of Oral and Craniomaxillofacial Implantology of the Ninth People's Hospital Affiliated with Shanghai Jiao Tong University, School of Medicine. Thirty-two patients with segmental mandibular defects because of tumor resection were enrolled in this study. Among the 32 patients, 16 had ameloblastomas (50\%). Oral squamous cell carcinoma were present in three patients $(9.4 \%), 10$ patients had keratocystic odontogenic tumors of the mandible $(31.2 \%)$, and myxomas were present in three patients (9.4\%). According to methods described by Jewer DD and colleagues, ${ }^{27}$ the mandibular defects were classified as two types: type L (lateral segment without a condyle) in 20 patients and type LCL (L, lateral segment without a condyle; $\mathrm{C}$, central segment including both canines) in 12 patients. All patients selected fulfilled the following criteria: (1) tumors in the maxillofacial region; (2) segmental mandibulectomy; (3) ilium graft and implant placement; (4) no history of neck irradiation; (5) informed consent; (6) no history of smoking or alcohol consumption; (7) no systemic disease; and (8) agreement to be followed over an extended period after reconstruction of oral function. The patients were divided into two groups based on whether they received immediate reconstruction (phase, 17 patients, implants were immediately placed in the ilium graft after vascular 
anastomosis) or delayed reconstruction with implants in autogenous ilium grafts (phase, 15 patients, after 6 months, implants were placed in the ilium grafted site). For patients to qualify for immediate reconstruction, the following criteria needed to be met: (1) tumors were removed with minimal tendency for recurrence; (2) patients were medically stable to tolerate the surgical procedures of immediate reconstruction; and (3) patients could afford the cost of immediate reconstruction. For delayed reconstruction, the criteria included: (1) time needed to observe for recurrence of the tumor, and (2) immediate reconstruction was cost prohibitive. The iliac grafts were completed by one group of surgeons, and all implant placements and prosthetic treatments were completed by another group of clinicians. The ethics committee of the Ninth People's Hospital affiliated with Shanghai Jiao Tong University, School of Medicine approved this study protocol in its entirety.

\section{The Reconstruction of Mandible Defects Using Phase I Protocol}

For patients in the phase I group, following tumor resection, the mandibular segmental defects were created, and an appropriately sized graft was obtained from the iliac crest. This graft was then sized to the mandibular contour of the defect and placed into the defect. The time of ischemia in the grafted bone was controlled by stabilizing the graft in the recipient site in less than 1.5 hours. After vascular anastomosis, a titanium plate was used for fixation of the bone graft. Two conventional implant (CI) systems (Straumann, Basel, Switzerland; Brånemark, Nobel Biocare, Göteborg, Sweden) were used, and these implants were placed into the grafted bone following stabilization of the graft. Two doctors performed the implant placements, each using only one of the two implant systems based on their clinical preference. A total of 55 CIs were used for the patients in phase I of the study, including 40 Straumann implants (SLA, sandblasted, large-grit, acid-etched) 3.3 to $4.8 \mathrm{~mm}$ in diameter and 10 to $16 \mathrm{~mm}$ in length, and 15 Brånemark implants (TiUnite) that were 3.75 or $4.3 \mathrm{~mm}$ in diameter and 10 to $13 \mathrm{~mm}$ in length. Moreover, as previously described, ${ }^{28}$ bone condensing was performed to enhance the bone density around the implants and stability of the implants. The defect site was primarily closed using skin islands or through direct suturing of the oral mucosa. After surgery, radiographs were taken to assess the location and directional angulation of the implants. All implants were allowed to heal subcutaneously, but most implants emerged through the soft tissue mucosa during the healing phase. After 4 to 6 months, radiography was used to verify osseointegration of the implants into the grafted bone. If osseointegration was achieved, prosthetic rehabilitation was performed at this time (5-6 months following bone grafting and implant placement).

\section{Reconstruction of Mandible Defects Using Phase II Protocol}

For patients in the phase II group, following tumor resection, the mandibular segmental defects were created, and an appropriately sized graft was obtained from the iliac crest and stabilized as was done in the phase I group. Four to six months after grafting, standard radiographic imaging was performed to assess the bone graft. If sufficient bone volume and no recurrence of oral tumor were confirmed, implants were placed in the area of the ilium graft. Bone condensing was also used to enhance the bone density around the implants and stability of the implants when the condition of bone density in the implant area was not ideal. One-staged surgery was used in the phase II group. A total of 55 CIs were used in patients in the phase II group, including 32 ITIs (International Team for Implantology [ITI], Institute Straumann AG, Basel, Switzerland) that were 4.1 to $4.8 \mathrm{~mm}$ in diameter and 10 to $14 \mathrm{~mm}$ in length, and 23 Brånemark that were 3.75 or $4.3 \mathrm{~mm}$ in diameter and 10 to $13 \mathrm{~mm}$ in diameter. After implant placement, radiographs were taken to check the location and direction of the implants. As was seen in most of the patients in the phase I group, implants were allowed to heal subcutaneously, and most implants emerged through the mucosa during the healing phase $(86.7 \%)$. Prosthetic procedures were performed 3 months after implant placement.

\section{Prosthetic Procedures}

Three (phase II) and six (phase I) months after implant placement, conventional prosthetic restoration of the implants was initiated. These procedures included exposure of the implant, placement of the healing cap, making of the impression after soft tissue healing, and fabrication of the final prosthesis. For patients in the phase I group, a second-stage implant surgery was completed to replace cover screws with healing caps at 5 or 6 months postgrafting/implant placement, and then prosthetic procedures were completed 1 week later, as described previously. ${ }^{29}$ Briefly, open-tray impression 
transfer copings (plastic trays with loopholes) were used to complete the impression using elastomeric impression material for the mandible. Master casts were poured, and a wax trial cast was generated for clinical evaluation and patient approval. Ceramic crowns and resin dentures were generated according to standard of care procedures. Most dentures were designed to be screw-retained to facilitate adequate hygienic maintenance. After a screw-retained framework was secured to the implants at a $35 \mathrm{Ncm}$ torque, the screw access holes were sealed using gutta-percha prior to composite fillings being placed on top of the framework. Following the delivery of the final dental prosthesis, patients were given oral hygiene instructions, prescribed a chlorhexidine rinse, and placed on recall programs to undergo periodontal maintenance every 6 months.

\section{Evaluation Criteria}

Patients in both groups received the same prosthetic procedures. A series of follow-up visits were performed during the 8 to 12 years following the completion of the final prostheses. The follow-ups were scheduled every 6 months following 1 year loading of the final prostheses. Moreover, five categories of data were recorded as follows: (1) implant success and survival rates - implants were defined as surviving if they fulfilled their supportive function and were stable when torque tested; the success criteria were consistent with those described by Albrektsson and colleagues; ${ }^{30}$ (2) marginal bone loss (MBL) panoramic and periapical images (if the local conditions were permissible) were taken to detect MBL in the peri-implant area; (3) soft tissue inflammation - these measures included sulcus bleeding index (BI; assessment of the bleeding tendency of the marginal peri-implant tissues at the mesial, distal, buccal, and lingual aspects of each implant), probing depths (of the mesial, distal, buccal, and lingual surfaces), suppuration (yes or no during the probing procedure), and measures of overall oral hygiene conditions (plaque index, gingival index, and calculus); (4) complications were recorded including abutment/ screw loosening, ceramic losses, food impactions, tooth crown renewals, and gingival hyperplasias; and (5) 1 year after completing prosthetic reconstruction, patient satisfaction (five indices) was evaluated including assessments of facial contour, function of the prosthesis, comfort level of the prosthesis, mouth opening, and pronunciation. Each score was reported using a scale of 0 to 2 points, as described previously. ${ }^{31}$
The software program SPSS 10.0 (SPSS Inc., Chicago, IL, USA) was used for statistical analysis. No adjustment of $p$ values for multiple testing was performed because of the descriptive nature of the study.

\section{RESULTS}

Thirty-two patients with mandibular defects, with a mean of age 42.4 (range of 24-61) years, underwent mandibular reconstruction to improve oral function with dental implants following autologous ilium grafting (from the anterior iliac spine) between January 2000 and October 2004. Dehiscence of the flap occurred in two patients in the phase II group and resulted in partial exposure of the graft, but no further complications were observed with these grafts. The survival rate of the bone grafts was $100 \%$ during the follow-up period. Bone loss associated with the graft was observed in five patients (two patients in the phase I group and three patients in phase II group). However, the loss of bone did not affect implant placement and functional oral reconstruction. Two patients experienced paresthesia at the donor site, and one patient presented with a slight gait disturbance after the ilium graft. The patients in the phase I group were prosthetically restored within 5 to 6 months after the bone graft, whereas patients in the phase II group were restored 8 to 10 months following grafting. A total of 110 implants were placed in iliac bone grafts, of which 55 implants were in the phase I group. All patients underwent reconstruction using implant-supported fixed prostheses that were screw- or bonding-retained (Table 1). Over the 8- to 12-year period of follow-up observations, two patients $(6.3 \%)$ dropped out because of tumor recurrence (one in phase I group had tumor recurrence 1.5 years after oral function reconstruction, and one in phase II group was 2 years). The cases of dropouts were excluded from the analysis. Five CIs failed, and four CIs were removed during the followup period. The 8- to 12-year cumulative survival and success rates were $96.4 \%$ and $91.8 \%$, respectively (Table 2). There were no significant differences of implant survival rate between the ITI system and Nobel system. The mean peri-implant bone loss ranged from 1.0 to $1.2 \mathrm{~mm}$ in this study over the 8 to 12 years of follow-up (Table 3 ). In some cases, severe bone loss occurred during the first year after the implants were placed, but bone loss remained relatively constant thereafter. The peri-implant hygienic parameters were 
TABLE 1 Clinical Features of Patients

\begin{tabular}{|c|c|c|}
\hline & Phase I Group $(n=17)$ & Phase II Group $(n=15)$ \\
\hline Age (years) & $41.6 \pm 3.2$ & $43.3 \pm 2.6$ \\
\hline Gender (male/female) & $9 / 8$ & $9 / 6$ \\
\hline Type of tumor $(n)$ & $\begin{array}{l}\text { Ameloblastoma (9), SCC (2), KOT (5), } \\
\text { Myxoma (1) }\end{array}$ & $\begin{array}{l}\text { Ameloblastoma (7), SCC (1), KOT (5), } \\
\text { Myxoma (2) }\end{array}$ \\
\hline Defect type $(n)$ & L (12), LCL (5) & L (8), LCL (7) \\
\hline Implants $(n)$ & $55($ Nobel $=15$, Straumann $=40)$ & $55($ Nobel $=23$, Straumann $=32)$ \\
\hline Length & $\begin{array}{l}10,12,13,14,16 \mathrm{~mm} \\
3.3,3.75,4.1,4.3,4.8 \mathrm{~mm}\end{array}$ & $\begin{array}{l}10,12,13,14,16 \mathrm{~mm} \\
3.75,4.1,4.3,4.8 \mathrm{~mm}\end{array}$ \\
\hline \multicolumn{3}{|l|}{ Diameter } \\
\hline Dropout $(n)$ & 1 & 1 \\
\hline
\end{tabular}

SCC, squamous cell carcinoma; KOT, keratozystic odontogenic tumor; LCL, L, lateral segment without a condyle and C, central segment including both canines.

measured at each follow-up assessment from each implant. The data showed that $72.2 \%$ of implants had a BI score between 0 and 1 in the first year of the study and that $77.8 \%$ of implants maintained a BI score between 0 and 1 at the final year (year 12). In contrast, the percentage of implants with a plaque index of score equal to 1 to 2 increased from $24.1 \%$ during the first year to $33.3 \%$ at the final year. A total of $13.9 \%$ of implants showed a calculus index score between 0.5 and 1 during the first year, and $11.1 \%$ presented with this index value in the final year of follow-up. All surgical and prosthetic complications during this 8- to 12-year study are listed in Table 4. In total, 26 maintenance procedures were required for all patients. There were three abutment/screw loosenings, four replacements for loss of ceramic prosthetic material, three cases of food impactions, five crowns in need of being redone, and 11 cases of gingival hyperplasias. The number of maintenance procedures required during the first, third, and fifth years of follow-up was 4,9 , and 7 , respectively. The above data show that the incidence of postoperative maintenance efforts was higher in the third year of follow-up, and the most frequent maintenance procedures were for the treatment of gingival hyperplasia. The 8- to 12-year follow-up program showed that the annual mean number of complications/repairs was 0.11 , or approximately 0.07 per patient in this study.

Twenty-six were fully satisfied, and six were partially satisfied with the results of reconstruction. Over $80 \%$ of the patients were fully satisfied with their oral function. Of the 32 patients (excluding the two lost to follow-up), 31 were fully satisfied with the facial contour. Three patients who were partially satisfied with their pronun- ciation (one in the phase I group and two in the phase II group) suffered from limited tongue motion. Two patients (one in the phase I group and one in the phase II group) were only partially satisfied with their mouth opening after oral reconstruction because of myofibrosis of soft tissue in the area of the bone defects. The patient satisfaction scores are summarized in Table 5. The restoration outcomes of four cases are illustrated in Figures 1,2, 3, and 4. Figures 1 and 2 show the results of two patients in the phase I group (one with an L-type mandibular bone defect and one with an LCL-type mandibular bone defect, resonance frequency analysis $=70$ ), and Figures 3 and 4 show the results from two patients in the phase II group (one with an L-type mandibular bone defect and one with an LCL-type mandibular bone defect).

\section{DISCUSSION}

Facial contours, mastication, normal speech, movements of the lower jaw, and impairment of the donor site must be taken into account when reconstructive surgery is performed for patients with segmental mandibular defects. It is not easy for clinicians to restore the oral function of patients who are in need of segmental mandibulectomies. An important part of dental implant therapy in restoring these sites involves bone reconstruction in the area of the bone defect. From alloplastic bone substitutes to the autogenous bone grafts, there are many options currently available. ${ }^{32-34}$ However, only ilium grafts were examined in this study. The long-term data confirmed that dental implants placed on autogenous ilium grafts are an effective method for reconstruction of these sites. 

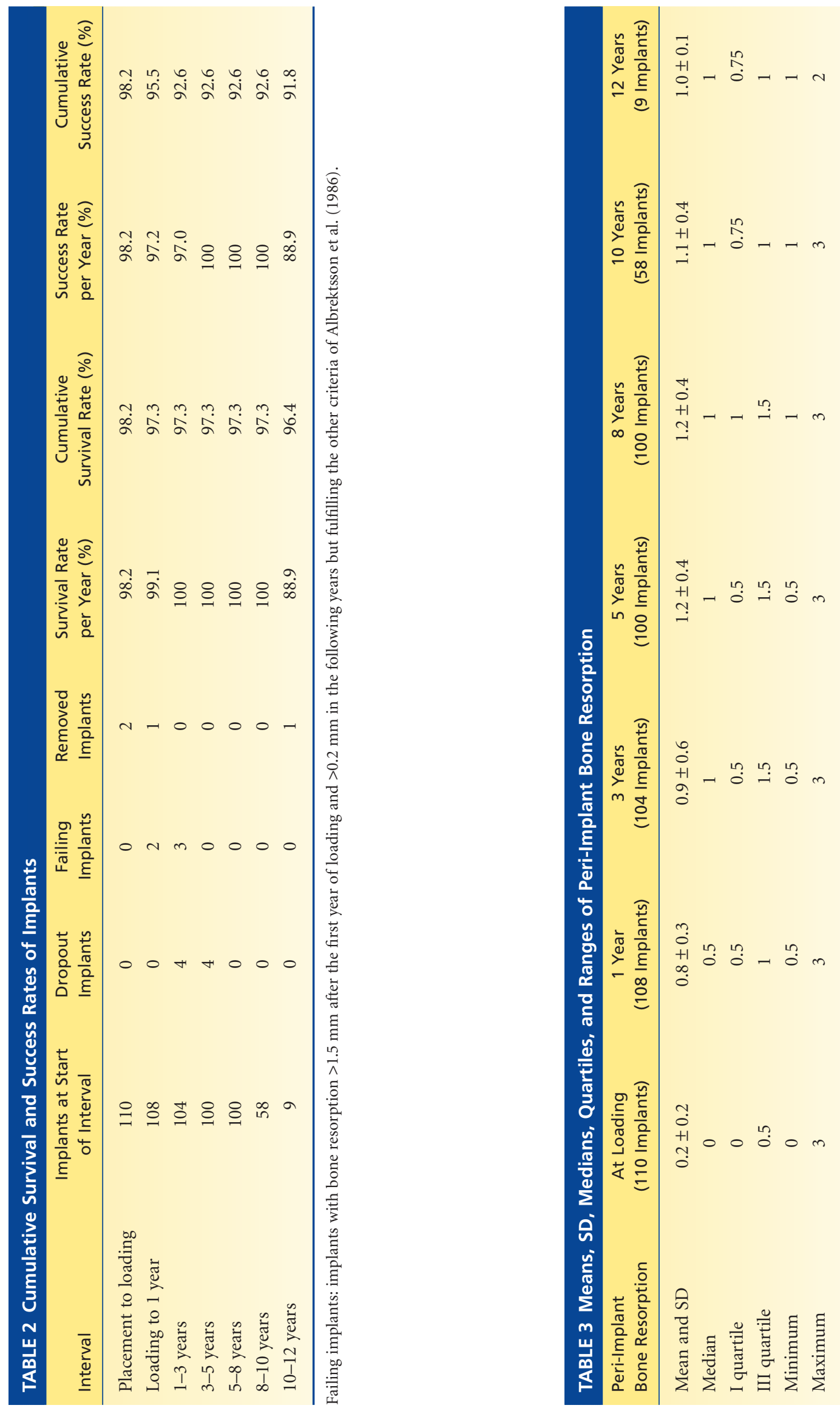
TABLE 4 Type of Prosthodontic Maintenance and Complications in Implant-Supported Fixed Dentures

\begin{tabular}{|c|c|c|c|c|c|c|c|}
\hline Parameters & 1 Year & 3 Years & 5 Years & 8 Years & 10 Years & 12 Years & Total \\
\hline Patients $(n)$ & 32 & 31 & 30 & 30 & 17 & 4 & 30 \\
\hline \multicolumn{8}{|l|}{ Implant component maintenance } \\
\hline Implant fracture & 0 & 0 & 0 & 0 & 0 & 0 & 0 \\
\hline Abutment/screw loosening & 0 & 1 & 0 & 1 & 1 & 0 & 3 \\
\hline Abutment/bar fracture & 0 & 0 & 0 & 0 & 0 & 0 & 0 \\
\hline \multicolumn{8}{|l|}{ Implant prosthodontic maintenance } \\
\hline Ceramic loss & 0 & 1 & 2 & 1 & 0 & 0 & 4 \\
\hline Food impaction (mesial or distal diastema) & 0 & 2 & 1 & 0 & 0 & 0 & 3 \\
\hline Tooth crown renewed make & 0 & 2 & 2 & 1 & 0 & 0 & 5 \\
\hline Peri/interimplant GH $(n)$ & 4 & 3 & 2 & 2 & 0 & 0 & 11 \\
\hline Total & 4 & 9 & 7 & 5 & 1 & 0 & 26 \\
\hline Interventions/year/patient & & & & & & & $0.11 \sim 0.07$ \\
\hline
\end{tabular}

$\mathrm{GH}$, gingival hyperplasia.

Although partial resorption of the bone graft was observed in these patients, the results showed that the ilium grafts achieved a $100 \%$ survival rate during the 12-year follow-up period. Successful bone reconstruction provided not only adequate facial contours but also created adequate support for the subsequent phases of implant placement and for restoration of oral biological functions. The cumulative survival and success rates for implants reached high levels $(96.4 \%$ and $91.8 \%$, respectively) during the 8- to 12 -year follow-up period. Although two implant types (ITI and Nobel) were used to reconstruct oral function, there were no significant differences of the cumulative survival and success rates between these two implant systems in the grafted area. Three patients presented with complications at the donor site after ilium grafting (two patients with paresthesia and one patient with a slight gait disturbance), although these symptoms declined after 2 years, and the patients understood and tolerated these complications of mandibular reconstruction.
The mean peri-implant bone resorption ranged from 1.0 to $1.2 \mathrm{~mm}$ in this study over the 8 to 12 years of follow-up. With regard to complications after oral functional reconstruction, three main issues were identified: (1) calculus accumulation; (2) gingival hyperplasia; and (3) bone resorption. A total of five implants failed in this study because of severe gingival hyperplasia and bone resorption in the peri-implant area. Furthermore, four implants were removed. The reasons for calculus accumulation may include the following: (1) loss of sublingual and submandibular glands injured or lost after tumor excision resulting in decreased saliva volume and difficulties in clearing debris following mastication; (2) limited tongue movement if the hypoglossal nerve is damaged or part of the tongue is resected also leading to difficulties clearing food debris following mastication; and (3) inadequate oral hygiene measures, such as brushing teeth carefully and fastidiously and rinsing following mastication. In this study, the highest calculus accumulation $(20.2 \%)$ occurred during the third year

\begin{tabular}{|c|c|c|c|c|c|}
\hline Facial Contour & & Prosthesis Comfort & Pronuciation & Mouth Opening & Prosthesis Function \\
\hline \multicolumn{6}{|l|}{ Phase I } \\
\hline Patients $(n=17)$ & $\begin{array}{l}16 \text { patients }=2, \\
\quad \text { one patient }=1\end{array}$ & $\begin{array}{l}15 \text { patients }=2, \\
\quad \text { two patients }=1\end{array}$ & $\begin{array}{l}16 \text { patients }=2, \\
\quad \text { one patient }=1\end{array}$ & $\begin{array}{l}16 \text { patients }=2, \\
\quad \text { one patient }=1\end{array}$ & $\begin{array}{l}15 \text { patients }=2, \\
\text { two patients }=1\end{array}$ \\
\hline \multicolumn{6}{|l|}{ Phase II } \\
\hline patients $(n=15)$ & 15 patients (2) & 15 patients (2) & $\begin{array}{l}13 \text { patients }=2, \\
\quad \text { two patients }=1\end{array}$ & $\begin{array}{l}14 \text { patients }=2, \\
\quad \text { one patient }=1\end{array}$ & $\begin{array}{l}13 \text { patients }=2, \\
\quad \text { two patients }=1\end{array}$ \\
\hline
\end{tabular}

0 , unsatisfied; 1 , partially satisfied; 2 , fully satisfied. 

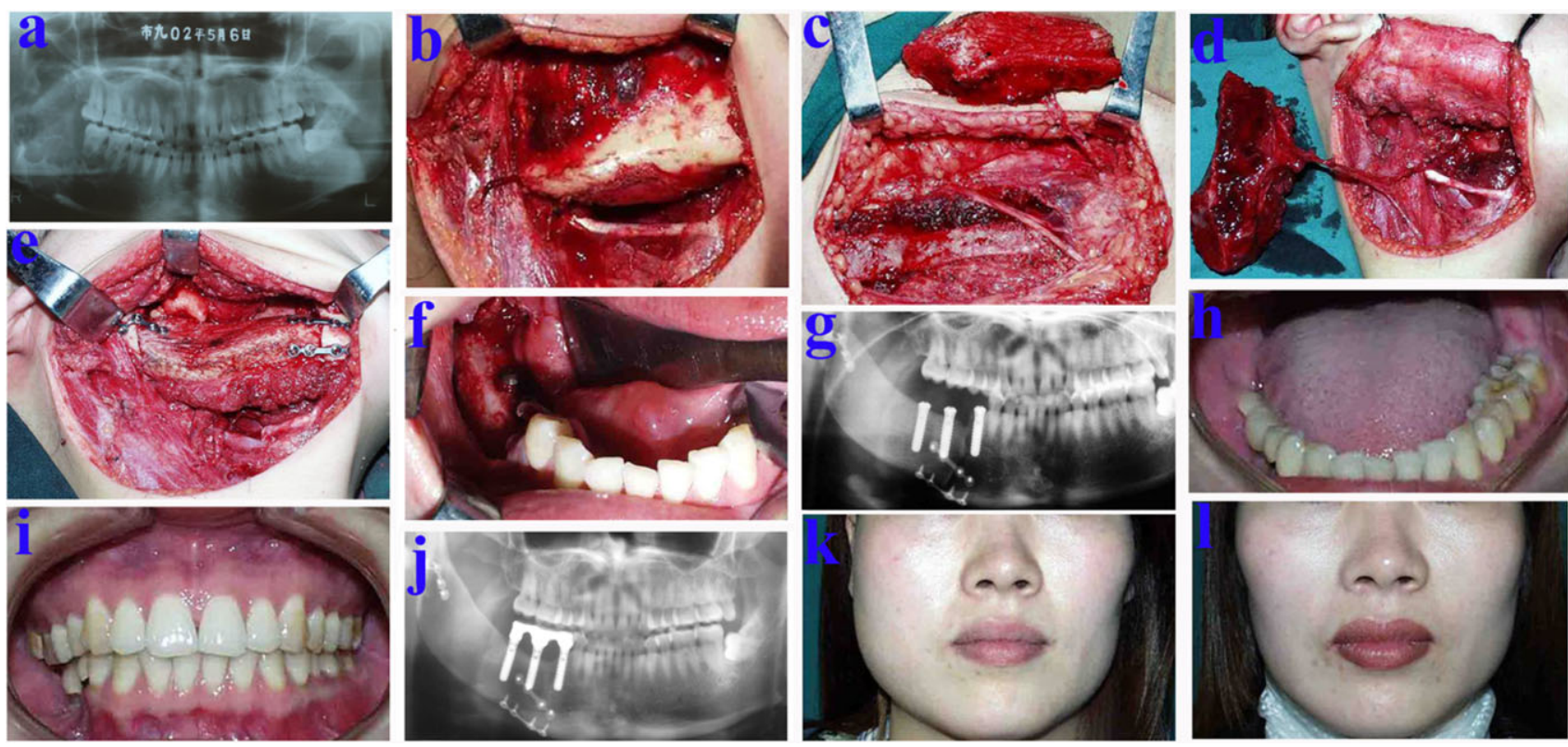

Figure 1 Clinical view of a mandibular defect reconstruction after tumor resection using conventional implants (CIs) (phase I with a lateral segment without a condyle [L]-type mandibular bone defect). A, tumor diagnosis using panorama; B-G, bone graft taken from the ilium and implant placement after tumor resection; H-J, implant-supported, fixed prosthetic rehabilitation; $\mathrm{K}-\mathrm{L}$, photograph of the patient before and after reconstruction.

after oral functional reconstruction. Therefore, it is important to debride calculus to prevent the development of soft tissue health issues in the peri-implant area. Some measures can be applied to maintain high standards of oral hygiene, ${ }^{35}$ including (1) using a "waterpik" oral irrigator to clear food debris, particularly in patients with lingual nerve damage or partial tongue excision; (2) strict compliance with a periodontal maintenance regimen ensuring that dentures are professionally cleaned every 6 months; and (3) incorporating family members into the hygiene regimen to help supervise or assist the patient in their oral hygiene. Severe gingival hyperplasia was observed in this study, and four implants were removed because of bone resorption in the peri-implant area caused by gingival hyperplasia. During the follow-up period, a total of 11 patients showed gingival hyperplasia. Four cases were treated using surgical removal of the hyperplastic tissue. In five cases, the fixed dentures were removed, and the gingival hyperplasia was resolved after 7 to 10 days. These cases showed good results, and no notable bone resorption was observed. However, in the two other cases, the
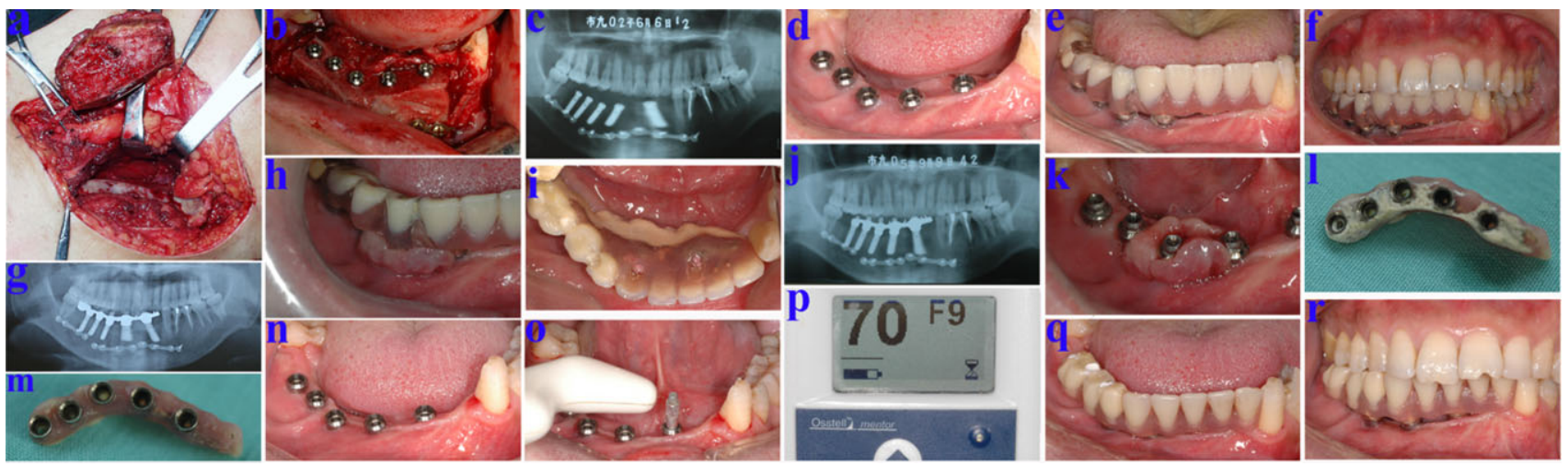

Figure 2 Clinical view of a mandibular defect reconstruction after tumor resection using conventional implants (CIs) (phase I with a LCL [L, lateral segment without a condyle and C, central segment including both canines]-type mandibular bone defect). A-D, bone graft taken from the ilium and implant placement after tumor resection; E-J, implant-supported, fixed prosthetic rehabilitation; $\mathrm{H}-\mathrm{N}$, managing complications because of calculus accumulation or gingival hyperplasia; $\mathrm{O}-\mathrm{P}$, checking the stability of the implants (RFA=70); Q-R, clinical results after treating complications. 

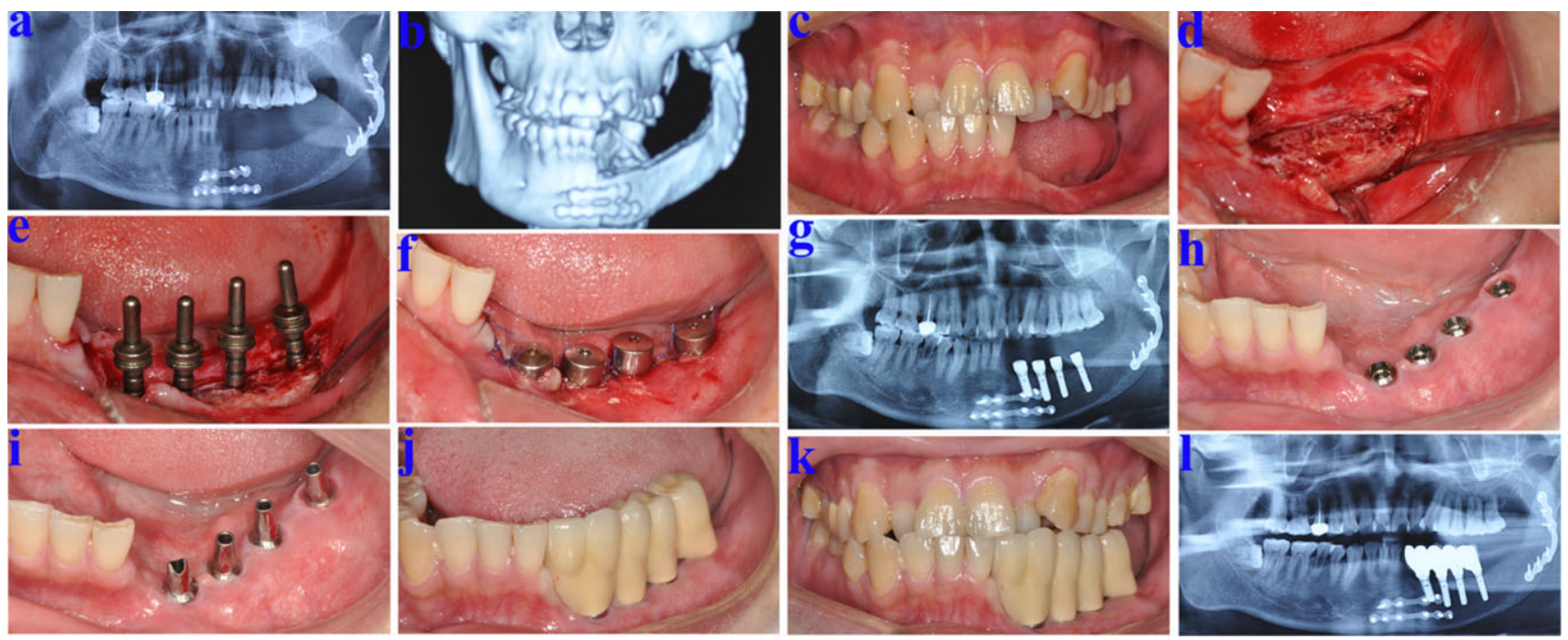

Figure 3 Clinical view of a mandibular defect reconstruction after tumor resection using conventional implants (CIs) (phase II with a lateral segment without a condyle [L]-type mandibular bone defect). A-C, clinical diagnosis using panorama and computed tomography; D-G, implant placement in the area of the ilium graft; H-L, implant-supported, fixed prosthetic rehabilitation.

surgical removal of the gingival hyperplasia failed. Because of the regular follow-ups and attentive oral hygiene practices, the annual mean number of complications/repair was lower $(0.11-0.07)$ per patient in this study. More importantly, over $80 \%$ of patients were fully satisfied with the reconstruction of oral function, including the facial contour, the function of their prosthesis, the comfort level of the prosthesis, and their mouth opening and enunciation. The patients with only partial satisfaction may have had excessively high expectations for the outcomes of the oral reconstruction.

Many previous reports have shown that the oral function of patients with bone defects in the jaw can be restored using dental implants based on autogenous bone grafts. ${ }^{36-38}$ However, there have been few prospec- tive studies on the restoration of oral function in tumor patients with a mandibular bone defect using dental implants placed only in autogenous ilium grafts. ${ }^{39,40}$ Furthermore, few reports have published data covering a long-term (i.e., 10-year) follow-up period following mandibular functional reconstruction. In 2008, Chiapasco $\mathrm{M}$ and colleagues demonstrated that bone defects with resection of mandibular tumors can be reconstructed with dental implant base on autogenous bone grafts taken from autogenous nonrevascularized calvarial or iliac bone grafts. ${ }^{41}$ The survival and success rates of implants placed in the reconstructed areas were $96.7 \%$ and $93.3 \%$, respectively, in a 9 -year retrospective study. Compared with nonrevascularized calvarial or iliac bone grafts, the main objective of this study was to
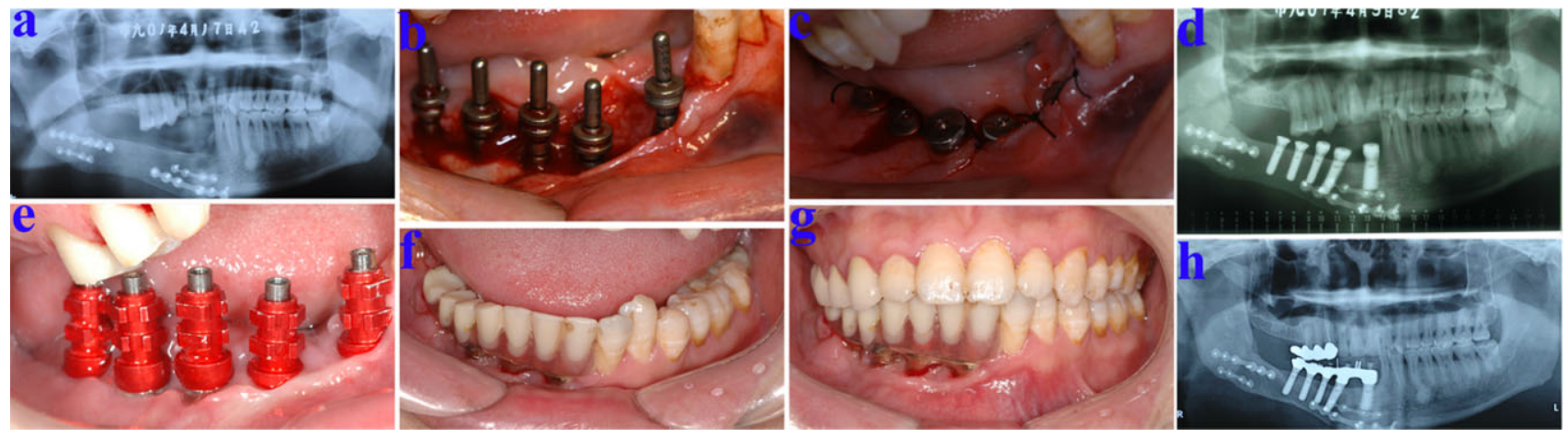

Figure 4 Clinical view of a mandibular defect reconstruction after tumor resection using conventional implants (CIs) (phase II with a LCL [L, lateral segment without a condyle and C, central segment including both canines]-type mandibular bone defect). A, clinical diagnosis using panorama; B-D, implant placement in the area of the ilium graft; E-H, implant-supported, fixed prosthetic rehabilitation. 
systematically evaluate the clinical efficacy of oral functional reconstruction only with the revascularized ilium in a retrospective study with 8 to 12 years of follow-up. The results of this study showed similar results of the survival and success rates of implants $(96.4 \%$ and $91.8 \%$, respectively). Therefore, our study further confirmed that resection of mandibular tumors with autogenous revascularized ilium grafts is an effective method for reconstructing the mandible.

\section{CONCLUSIONS}

The results of this study indicate the following: (1) autogenous ilium bone grafting is an effective means to reconstruct the lower jaw of patients following tumor resection resulting in segmental mandibular bone defects; (2) this technique demonstrates an excellent prognosis for restoring oral function in patients with mandibular defects, based on the high survival and success rates of the implants placed in the reconstructed areas; (3) patients expressed a high level of satisfaction with the restoration of their oral function; and (4) there was no significant difference between phase I and II groups regarding the clinical efficacy of oral functional reconstruction. These results also demonstrate that peri-implant infection, calculus accumulation, or gingival hyperplasia remain a disturbingly common problem associated with this type of treatment. Therefore, it is important to regularly review patient oral hygiene instructions to prevent the above complications from occurring.

\section{ACKNOWLEDGMENTS}

This study was funded by the Combined Engineering and Medical Project of Shanghai Jiao Tong University (YG2012MS32), Science and Technology Commission of Shanghai Municipality (13ZR1424000), the National Natural Science Foundation of China (81100788, 31370983, 81371190), the Key Project of Chinese Ministry of Education (212080), Grants for Scientific Research of BSKY(XJ201109), and the Young Top-notch Talent Support Scheme from Anhui Medical University.

\section{REFERENCES}

1. Kudo K, Shoji M, Yokota M, Fujioka Y. Evaluation of mandibular reconstruction techniques following resection of malignant tumors in the oral region. J Oral Maxillofac Surg 1992; 50:14-21.
2. Larson DL, Sanger JR. Management of the mandible in oral cancer. Semin Surg Oncol 1995; 11:190-199.

3. Rogers SN, Devine J, Lowe D, Shokar P, Brown JS, Vaugman ED. Longitudinal health-related quality of life after mandibular resection for oral cancer: a comparison between rim and segment. Head Neck 2004; 26:54-62.

4. Barttelbort SW, Ariyan S. Mandible preservation with oral cavity carcinoma: rim mandibulectomy versus sagittal mandibulectomy. Am J Surg 1993; 166:411-415.

5. Namaki S, Matsumoto M, Ohba H, Tanaka H, Koshikawa N, Shinohara M. Masticatory efficiency before and after surgery in oral cancer patients: comparative study of glossectomy, marginal mandibulectomy and segmental mandibulectomy. J Oral Sci 2004; 46:113-117.

6. Rana M, Warraich $\mathrm{R}$, Kokemuller $\mathrm{H}$, et al. Reconstruction of mandibular defects - clinical retrospective research over a 10-year period. Head Neck Oncol 2011; 3:23, 1-7.

7. Adell R, Lekholm U, Rockler B, Branemark PI. A 15-year study of osseointegrated implants in the treatment of the edentulous jaw. Int J Oral Surg 1981; 10:387-416.

8. Keller EE. Reconstruction of the severely atrophic edentulous mandible with endosseous implants: a 10-year longitudinal study. J Oral Maxillofac Surg 1995; 53:305-320.

9. Keller EE, Desjardins RP, Eckert SE, Tolman DE. Composite bone grafts and titanium implants in mandibular discontinuity reconstruction. Int J Oral Maxillofac Implants 1988; 3:261-267.

10. Cordeiro PG, Disa JJ, Hidalgo DA, Hu QY. Reconstruction of the mandible with osseous free flaps: a 10-year experience with 150 consecutive patients. Plast Reconstr Surg 1999; 104:1314-1320.

11. Snyder CC, Bateman JM, Davis CW, Warden GD. Mandibulo-facial restoration with live osteocutaneous flaps. Plast Reconstr Surg 1970; 45:14-19.

12. Disa JJ, Cordeiro PG. Mandible reconstruction with microvascular surgery. Semin Surg Oncol 2000; 19:226-234.

13. Urken $\mathrm{ML}$, Weinberg $\mathrm{H}$, Vickery $\mathrm{C}$, Buchbinder $\mathrm{D}$, Lawson W, Biller HF. Oromandibular reconstruction using microvascular composite free flaps. Report of 71 cases and a new classification scheme for bony, soft-tissue, and neurologic defects. Arch Otolaryngol Head Neck Surg 1991; 117: $733-744$

14. Burkey BB, Coleman JR Jr. Current concepts in oromandibular reconstruction. Otolaryngol Clin North Am 1997; 30:607-630.

15. Hidalgo DA, Pusic AL. Free-flap mandibular reconstruction: a 10-year follow-up study. Plast Reconstr Surg 2002; 110: 438-449.

16. Frodel JL, Sykes JM, Jones JL. Evaluation and treatment of vertical microgenia. Arch Facial Plast Surg 2004; 6:111119.

17. Jacobsen C, Kruse A, Lübbers HT, et al. Is Mandibular Reconstruction Using Vascularized Fibula Flaps and Dental 
Implants a Reasonable Treatment? Clin Implant Dent Relat Res 2012. DOI: 10.1111/cid.12004

18. Lawson W, Biller HF. Mandibular reconstruction: bone graft techniques. Otolaryngol Head Neck Surg 1982; 90:589594.

19. Tidstrom KD, Keller EE. Reconstruction of mandibular discontinuity with autogenous iliac bone graft: report of 34 consecutive patients. J Oral Maxillofac Surg 1990; 48:336346.

20. Miles BA, Goldstein DP, Gilbert RW, Gullane PJ. Mandible reconstruction. Curr Opin Otolaryngol Head Neck Surg 2010; 18:317-322.

21. Dimitriou R, Mataliotakis GI, Angoules AG, Kanakaris NK, Giannoudis PV. Complications following autologous bone graft harvesting from the iliac crest and using the RIA: a systematic review. Injury 2011; 42(Suppl 2):S3-15.

22. Jung HD, Nam W, Cha IH, Kim HJ. Reconstruction of combined oral mucosa-mandibular defects using the vascularized myoosseous iliac crest free flap. Asian Pac J Cancer Prev 2012; 13:4137-4140.

23. Sekine J, Sano K, Ikeda H, Inokuchi T. Rehabilitation by means of osseointegrated implants in oral cancer patients with about four to six years follow-up. J Oral Rehabil 2006; 33:170-174.

24. Neligan PC. Head and neck reconstruction. Plast Reconstr Surg 2013; 131:260e-269e.

25. Freier K, Mertens C, Engel M, Hoffmann J. Therapeutic strategies for the reconstruction of extensive mandibular defects. HNO 2013; 61:551-558.

26. Simon EN, Merkx MA, Kalyanyama BM, Shubi FM, Stoelinga PJ. Immediate reconstruction of the mandible after resection for aggressive odontogenic tumours: a cohort study. Int J Oral Maxillofac Surg 2013; 42:106-112.

27. Jewer DD, Boyd JB, Manktelow RT, et al. Orofacial and mandibular reconstruction with the iliac crest free flap: a review of 60 cases and a new method of classification. Plast Reconstr Surg 1989; 84:391-403.

28. Abels N, Schiel HJ, Hery-Langer G, Neugebauer J, Engel M. Bone condensing in the placement of endosteal palatal implants: a case report. 1999; 14:849-852.

29. Baig MR, Rajan G, Rajan M, eds. Edentulous arch treatment with a CAD/CAM screw-retained framework and cemented crowns: a clinical case report. J Oral Implantol 2009; 35:295299.

30. Albrektsson T, Zarb G, Worthington P, Eriksson AR. The long-term efficacy of currently used dental implants: a review and proposed criteria of success. Int J Oral Maxillofac Implants 1986; 1:11-25.

31. Huang W, Wu Y, Zou D, et al. Long-term results for maxillary rehabilitation with dental implants after tumor resection. Clin Implant Dent Relat Res 2012. DOI: 10.1111/ j.1708-8208.2012.00481.x

32. Trautvetter W, Kaps C, Schmelzeisen R, Sauerbier S, Sittinger M. Tissue-engineered polymer-based periosteal bone grafts for maxillary sinus augmentation: five-year clinical results. J Oral Maxillofac Surg 2011; 69:2753-2762.

33. Mordenfeld A, Albrektsson T, Hallman M. A 10-year clinical and radiographic study of implants placed after maxillary sinus floor augmentation with an 80:20 mixture of deprotenized bovine bone and autogenous bone. Clin Implant Dent Relat Res 2012. DOI: 10.1111/cid.12008

34. Dottore AM, Kawakami PY, Bechara K, et al. Stability of implants placed in augmented posterior mandible after alveolar osteotomy using resorbable nonceramic hydroxyapatite or intraoral autogenous bone: 12-month follow-up. Clin Implant Dent Relat Res 2012. DOI: 10.1111/cid.12010

35. Sharma NC, Lyle DM, Qaqish JG, Schuller R. Comparison of two power interdental cleaning devices on plaque removal. J Clin Dent 2012; 23:17-21.

36. Fujiki M, Miyamoto S, Sakuraba M, Nagamatsu S, Hayashi R. A comparison of perioperative complications following transfer of fibular and scapular flaps for immediate mandibular reconstruction. J Plast Reconstr Aesthet Surg. 2013; 66:372-375.

37. Bianchi B, Ferri A, Ferrari S, Copelli C, Boni P, Sesenna E. Iliac crest free flap for maxillary reconstruction. J Oral Maxillofac Surg 2010; 68:2706-2713.

38. Klein MO, Grotz KA, Walter C, Wegener J, Wagner W, Al-Nawas B. Functional rehabilitation of mandibular continuity defects using autologous bone and dental implants - prognostic value of bone origin, radiation therapy and implant dimensions. Eur Surg Res 2009; 43:269-275.

39. Sarukawa S, Noguchi T, Oh-iwa I, et al. Bare bone graft with vascularised iliac crest for mandibular reconstruction. J Craniomaxillofac Surg 2012; 40:61-66.

40. Modabber A, Gerressen M, Stiller MB, et al. Computerassisted mandibular reconstruction with vascularized iliac crest bone graft. Aesthetic Plast Surg 2012; 36:653-659.

41. Chiapasco M, Colletti G, Romeo E, Zaniboni M, Brusati R. Long-term results of mandibular reconstruction with autogenous bone grafts and oral implants after tumor resection. Clin Oral Implants Res 2008; 19:1074-1080. 